\title{
Skin wound healing, ischemia-reperfusion injury and nerve regeneration: Similarities in the sequential events and molecular basis
}

\author{
MM Al-Qattan MB Bs FRCSC, WM Al-Kattan MD Bs FRCSC
}

\begin{abstract}
MM Al-Qattan, WM Al-Kattan. Skin wound healing, ischemiareperfusion injury and nerve regeneration: Similarities in the sequential events and molecular basis. Can J Plast Surg 2004;12(3):131-133.

Skin wound healing, ischemia-reperfusion injury and nerve regeneration are three important topics for the hand surgeon. The events and molecular basis for each of these three topics are very complex, and previous review articles have discussed each topic separately. The present review demonstrates and comments on the similarities in the sequential events and molecular basis among skin wound healing, ischemia-reperfusion injury and nerve regeneration.
\end{abstract}

Key Words: Cytokines; Ischemia; Nerve; Reperfusion; Skin; Wound
Cicatrisation des lésions cutanées, lésions de reperfusion et régénération des nerfs : ressemblances quant à la séquence d'événements et à la structure moléculaire

La cicatrisation des lésions cutanées, les lésions de reperfusion et la régénération des nerfs sont trois éléments importants pour le chirurgien de la main. La séquence d'événements et la structure moléculaire de chacun sont très complexes; les trois sujets ont déjà fait l'objet de discussion dans des articles précédents, mais ils étaient considérés isolément. Les auteurs du présent examen relèvent les ressemblances entre les trois phénomènes quant à la séquence d'événements et à la structure moléculaire, puis les commentent.
Gkin wound healing, ischemia-reperfusion injury and nerve Sregeneration are three important topics for the hand surgeon. The events and molecular basis for each of these three topics are very complex, and previous review articles have discussed each topic separately (1-7).

The aim of the present review is to demonstrate and comment on the similarities in the sequential events and molecular basis among skin wound healing, ischemia-reperfusion injury and nerve regeneration. Before commenting on the similarities, a brief account on each topic will be given.

\section{SKIN WOUND HEALING}

\section{The inflammatory phase}

Immediately following skin wounding, cytokines, including interleukin-1 (IL-1), are released by endothelial cells and keratinocytes. Platelets forming the primary hemostatic plug secrete tumour necrosis factor-alpha (TNF- $\alpha)$, platelet derived growth factors (PDGF), transforming growth factor-beta (TGF- $\beta$ ) and fragments of fibronectins (Fn). Within minutes of injury, P-selectin (an adhesion molecule) is expressed on the endothelial cell surface which facilitates preferential neutrophil binding and, hence, neutrophils are the first inflammatory cells that enter the wound. P-selectin expression on the endothelial cell is transient, however, and is followed by endothelial E-selectin expression which is induced by the platelet-derived TNF- $\alpha$ and the keratinocyte-derived IL-1. E-selectin expression occurs $2 \mathrm{~h}$ to $6 \mathrm{~h}$ following the injury and it facilitates both monocyte and neutrophil binding. Approximately $12 \mathrm{~h}$ after injury, IL-1, TNF- $\alpha$ and interferongamma induce endothelial intercellular adhesion molecule (ICAM) and vascular cell adhesion molecule expression with selective recruitment of monocytes and lymphocytes into the wound. Further monocyte migration occurs along chemotactic gradients in response to leukotriene $\mathrm{B}_{4}$ and $\mathrm{Fn}$. Monocytes in the wound differentiate into macrophages which are essential to wound healing and secrete several factors including PDGF, TGF- $\beta$ and basic-fibroblast growth factor (b-FGF) which initiates the second phase of wound healing. Lymphocytes are also important in wound healing because they exert both stimulatory (TGF- $\beta$ ) and inhibitory (interferon-gamma) signals on all aspects of fibroblast activity.

\section{The fibroblasia phase}

Within $48 \mathrm{~h}$, fibroblasts appear in the wound and are stimulated by PDGF and TGF- $\beta$ to synthesize collagen (mainly type III) and matrix components, including Fn. Ingrowth of capillaries into the wound occurs in response to b-FGF.

\section{The maturation phase}

Maturation of the scar occurs three weeks after injury. This includes several events such as regression of wound capillaries, reorientation of collagen fibrils (in response to stress), inhibition of fibroblast secretion of collagen and matrix (via a negative feedback loop, interferons and reduction of local TGF- $\beta$ ), replacement of the early type III with type I collagen (this requires collagenase activity) and collagen cross-linkage.

\section{Epithelialization and wound contraction}

Within hours of wounding, epithelialization is stimulated by three main factors: epidermal growth factor, TGF- $\alpha$ and FGF-7 (also known as keratinocyte growth factor). Movement of 
keratinocytes is facilitated by their expression of surface $\alpha_{5} \beta_{1}$ integrin that are Fn receptors. In primary wound healing, the wound edges are bridged by migrating keratinocytes within $48 \mathrm{~h}$. In secondary wound healing, b-FGF, TGF- $\beta$ and PDGF activities are greatly increased to induce granulation tissue formation with subsequent appearance of myofibroblasts and wound contraction. Keratinocytes, with their surface integrins, migrate from the wound margin over the granulation tissue matrix.

\section{ISCHEMIA-REPERFUSION INJURY}

\section{The ischemic insult}

Ischemia leads to tissue hypoxia and depletion of cellular energy. Acting as a second messenger, calcium triggers the activation of several enzymes crucial to the production of inflammatory mediators, including the conversion of xanthine dehydrogenase to xanthine oxidase.

\section{Reperfusion with oxygen radical production}

Once the vascular supply is re-established, oxygen replenishment fosters enzymatic reactions leading to oxygen radical production, including the superoxide radical, hydrogen peroxide and the hydroxyl radical. These radicals cause direct damage to endothelial cells and induce the production of inflammatory mediators.

\section{Production of inflammatory mediators}

Although there is a long list of inflammatory mediators, the mediators important in reperfusion injury are histamine, platelet activating factor, leukotriene $\mathrm{B}_{4}$, thromboxane $\mathrm{A}_{2}, \mathrm{TNF}-\alpha$ and IL-1. These mediators initiate rolling of leukocytes along the venules.

\section{Rolling of leukocytes along the venules}

The next major step in reperfusion injury is the rolling of leukocytes along the endothelium of the venules of the reperfused tissue. Rolling of leukocytes occurs in two phases. In the early phase, P-selection (which is expressed on the endothelial cell surface) interacts with leukocytes. In the late phase, E-selectin replaces P-selectin on the endothelial surface and interacts with leukocytes. In the late rolling phase, leukocytes also express L-selectins on their surface.

\section{Adherence of leukocytes to the venules}

All the previous steps of reperfusion injury occur within a few minutes of re-establishment of circulatory flow to the ischemic tissue. The next major event is adherence of leukocytes to the endothelial cells of the venules. This adherence occurs by the interaction of $\beta_{2}$ (CD18) integrins (on the surface of leukocytes) and the endothelial ICAM.

\section{Arteriolar vasoconstriction}

It is now well established that leukocyte adherence to the venules is associated with a deficiency of local endothelial production of nitric oxide (NO), which leads to arteriolar vasoconstriction, a terminal step of reperfusion injury. The end result of reperfusion injury is a low-flow state with subsequent intravascular thrombosis.

\section{NERVE WOUND HEALING}

Following nerve transection and repair, the proximal segment provides the regenerating axons (growth cone) and the distal segment undergoes Wallerian degeneration in preparation for receiving these regenerating axons. The present review will concentrate on the events in the distal segment, where there is an interaction between growth factors, cytokines and adhesion molecules (similar to skin wound healing and reperfusion injury events).

The Schwann cell is the master of the distal nerve segment and has several roles in the repair process. Following nerve transection, the interaction between the axon and Schwann cell is altered sufficiently such that the Schwann cell changes from a supporting cell into a phagocytic cell. Schwann cells (and macrophages) phagocytose the myelin, which over a period of two to three weeks undergoes degeneration. During the same time, the distal axon completely disappears. The remnant of the axon-Schwann cell relationship will be only the Schwann cell nucleus, cytoplasm and the basal lamina. This degenerated system is known as the band of Bungner, which acts a scaffold and guides the new sprouting axons. A proximal single axon may yield as many as 10 or 15 sprouts. In myelinated nerves, several sprouts within the Schwann cell enclosure will begin to be myelinated and this grouping has been termed the regenerating unit.

Schwann cells also produce several neurotrophins and neurotrophic factors that support the regenerating axons. Schwann cells in the distal segment begin to produce nerve growth factor (NGF) at a peak level within $24 \mathrm{~h}$ and a 10 - to 15-fold level is maintained for at least two weeks after axotomy. The maintenance of high levels of NGF is regulated by IL-1 from macrophages in the distal nerve segment. Similarly, brain-derived neurotrophic factor levels increase several times in the distal segment and reaches its maximum four weeks after injury. On the other hand, ciliary neurotrophic factor is present at a high level in Schwann cells of intact nerves. Nerve transection causes a marked decrease in ciliary neurotrophic factor levels which disappears from Schwann cells 30 days after denervation, reappearing with reinnervation. Schwann cells also produce insulin-like growth factors and present laminin in its basal lamina which will support the sprouting axons. Furthermore, Schwann cells express adhesion molecules (neural cell adhesion molecules, neural glial cell adhesion molecules, myelin-associated glycoprotein and cadherins) which provide the Schwann cell-regenerating axon contact. Finally, Schwann cells play a major role in the proximal stump to reduce neuronal $\mathrm{NO}$ synthase expression, which is an enzyme necessary for the synthesis of $\mathrm{NO}$, a free radical compound believed to signal neuronal death. Thus, Schwann cells help enhance axonal regeneration by damping $\mathrm{NO}$ synthase expression.

\section{SIMILARITIES OF HEALING}

Similarities between the inflammatory phase of wound healing and the leukocyte rolling/adherence phases of reperfusion injury

In both skin wound healing and reperfusion injury, there is sequential expression of three adhesion molecules on the endothelial surface: P-selectin, then E-selectin and lastly, ICAM/vascular cell adhesion molecule. However, the timing and function of the expression varies (Table 1).

Similarities between nerve healing and skin wound healing Wound healing in nerves as a tissue is similar to skin wound healing (1). The injury to blood vessels after nerve transection allows neutrophils, monocytes, lymphocytes and platelets to 
TABLE 1

Sequential expression of adhesion molecules on the endothelial surface in skin wound healing and reperfusion injury

\begin{tabular}{|c|c|c|c|c|}
\hline \multirow{2}{*}{$\begin{array}{l}\text { Adhesion molecule } \\
\text { on the endothelium }\end{array}$} & \multicolumn{2}{|c|}{ Timing of expression following } & \multicolumn{2}{|c|}{ Function of the expressed adhesion molecule in } \\
\hline & Skin wounding & Reperfusion injury & Skin wounding & Reperfusion injury \\
\hline P-selectin & Few minutes & $1 \mathrm{~min}$ & $\begin{array}{l}\text { Initial migration of } \\
\text { neutrophils to the wound }\end{array}$ & $\begin{array}{l}\text { Early rolling phase of } \\
\text { leukocytes }\end{array}$ \\
\hline E-selectin & $2 \mathrm{~h}$ to $6 \mathrm{~h}$ & $2 \min$ & $\begin{array}{l}\text { Late migration of neutrophils } \\
\text { and monocytes }\end{array}$ & $\begin{array}{l}\text { Late rolling phase of } \\
\text { leukocytes }\end{array}$ \\
\hline ICAM/VCAM & $12 \mathrm{~h}$ & $3 \mathrm{~min}$ to $5 \mathrm{~min}$ & $\begin{array}{c}\text { Further migration of neutrophils, } \\
\text { monocytes and lymphocytes }\end{array}$ & $\begin{array}{l}\text { Adherence phase of } \\
\text { leukocytes }\end{array}$ \\
\hline
\end{tabular}

ICAM Intercellular adhesion molecule; VCAM Vascular cell adhesion molecule

enter the wounded nerve, the tissue. In other words, the 'inflammatory phase' of wound healing in nerves exists and probably has the same sequence of events shown in Table 1. Similarly, the 'fibroplasia phase' also exists in nerve healing. The regenerated axon has virtually no intrinsic strength. The strength of the nerve cell comes through collagen synthesis from the fibroblasts of the epineurium and perineurium. However, excessive scar formation may interfere with the distal passage of axons. Furthermore, excessive tension across the nerve suture line will increase the degree of fibrosis from fibroblasts and this will impair the nerve healing process. The growth of sprouting axons into the bands of Bungner under the influence of growth factors may be considered as the 'proliferative phase' of wound healing in the nerve. Finally, in the 'maturation phase' of nerve healing, there is an increase in the tensile strength of the nerve repair site, and later there is maturation of the regenerating neural unit once distal contact has been made with the appropriate sensory end-organ.

IL- 1 and TNF- $\alpha$ are the main cytokines initiating the events in skin wound healing, reperfusion injury and nerve regeneration

Cytokines are small proteins that act as signals between cells to regulate responses to injury and infection (8). Although there is a long list of cytokines (8), IL-1 and TNF- $\alpha$ are the main cytokines initiating the events in skin wound healing, reperfusion injury and nerve regeneration. Expression of adhesion molecules (selectins and ICAM) on the endothelial cell during the inflammatory phase of skin wound healing occurs in response to IL-1 and TNF- $\alpha$. This results in the entry of various inflammatory cells and monocytes into the wound. Similarly, expression of P- and E-selectins on the endothelial surface in reperfusion injury occurs in response to IL-1 and TNF- $\alpha$. This results in the initiation of rolling of leukocytes along the venules. Finally, IL-1 plays an important role in initiating the molecular events in the distal segment of regenerating nerves. IL-1 is secreted from macrophages in the distal nerve segment to maintain a high level of NGF. NGF level in the distal segment reaches a peak level within $24 \mathrm{~h}$ and a 10 - to 15 -fold level is maintained for at least two weeks after axotomy. Elevated levels of NGF will then initiate and promote axonal regeneration.

\section{REFERENCES}

1. Dellon AL. Wound healing in nerve. Clin Plast Surg 1990;17:545-70.

2. Kerrigan CL, Stotland MA. Ischemia reperfusion injury: A review. Microsurgery 1993;14:165-75.

3. Pang CY, Forrest CR, Mounsey R. Pharmacologic intervention in ischemia-induced reperfusion injury in the skeletal muscle. Microsurgery 1993;14:176-82.

4. Thomas DW, O'Neill ID, Harding KG, Shepherd JP. Cutaneous wound healing: A current prospective. J Oral Maxillofac Surg 1995;53:442-7.

5. Al-Qattan MM. Ischaemia reperfusion injury. Implications for the hand surgeon. J Hand Surg [Br] 1998;23:570-3.

6. Frostick SP, Yin Q, Kemp GJ. Schwann cells, neurotrophic factors and peripheral nerve regeneration. Microsurgery 1998;18:397-405.

7. Thanos PK, Okajima S, Terzis JK. Ultrastructure and cellular biology of nerve regeneration. J Reconstr Microsurg 1998;14:423-36.

8. Remick DG. Cytokines: A primer for plastic surgeons. Ann Plast Surg 1995;35:549-59. 